\title{
Universiteit
}

Leiden

The Netherlands

\section{Dynamics of urban and rural housing stocks in China}

Hu, M.; Bergsdal, H.; Voet, E. van der; Huppes, G.; Muller, D.B.

\section{Citation}

Hu, M., Bergsdal, H., Voet, E. van der, Huppes, G., \& Muller, D. B. (2010). Dynamics of urban and rural housing stocks in China. Building Research And Information, 38(3), 301-317.

doi:10.1080/09613211003729988

Version: $\quad$ Publisher's Version

License: $\quad$ Licensed under Article 25fa Copyright Act/Law (Amendment Taverne)

Downloaded from: https://hdl.handle.net/1887/3193706

Note: To cite this publication please use the final published version (if applicable). 


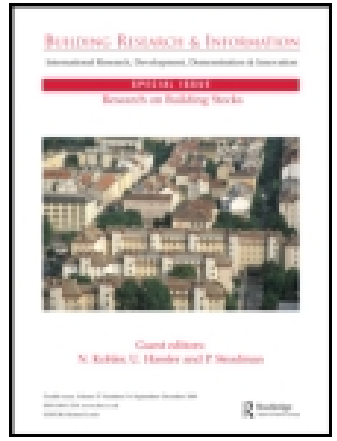

Building Research \& Information

\section{Dynamics of urban and rural housing stocks in China}

Mingming Hu , Håvard Bergsdal , Ester van der Voet , Gjalt Huppes \& Daniel B. Müller

To cite this article: Mingming Hu , Håvard Bergsdal , Ester van der Voet, Gjalt Huppes \& Daniel B. Müller (2010) Dynamics of urban and rural housing stocks in China, Building Research \& Information, 38:3, 301-317, DOI: 10.1080/09613211003729988

To link to this article: https://doi.org/10.1080/09613211003729988

册 Published online: 21 Apr 2010.

Submit your article to this journal 준

Џlll Article views: 2826

Q View related articles $\sqsubset$

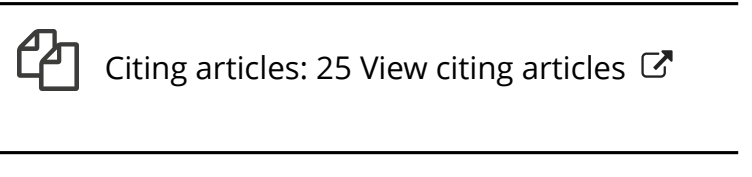




\title{
Dynamics of urban and rural housing stocks in China
}

\author{
Mingming $\mathrm{Hu}^{1,2}$, Håvard Bergsdal ${ }^{3}$, Ester van der Voet ${ }^{2}$, Gjalt Huppes ${ }^{2}$ and Daniel B. Müller ${ }^{3}$ \\ ${ }^{1}$ Faculty of Construction Management and Real Estate, Chongqing University, Chongqing 400015, P. R.China \\ E-mail: mingminghu@cqu.edu.cn \\ ${ }^{2} \mathrm{CML}$ - Institute of Environmental Sciences, Leiden University, Einsteinweg 2, NL-2333 CC Leiden, \\ the Netherlands \\ E-mails:hu@cml.leidenuniv.nl, voet@cml.leidenuniv.nl and huppes@cml.leidenuniv.nl \\ ${ }^{3}$ Department of Hydraulic and Environmental Engineering, Norwegian University of Science and \\ Technology, S. P. Andersens vei 5, N-7491 Trondheim, Norway \\ E-mails: havard.bergsdal@ntnu.no and daniel.mueller@ntnu.no
}

\begin{abstract}
The massive migration flows from rural to urban areas in China, combined with an expected decline in the total population over the next decades, leads to two important challenges for China's housing: the growth of its urban housing stock and the shrinkage of rural housing. The rural and urban housing systems in China were analyzed using a dynamic material flow analysis model for the period 1900-2100 for several scenarios assuming different development paths for population, urbanization, housing demand per capita, and building lifetime. The simulation results indicate that new housing construction is likely to decline for several decades due to the fast growth over the past 30 years and the expected increased longevity of dwellings. Such an oscillation of new construction activity would have significant implications for the construction industry, employment, raw material demand, and greenhouse gas emissions to produce the construction materials. Policy and practical options for mitigating the negative impacts are considered.
\end{abstract}

Keywords: building stocks, construction demand, dynamic material flow analysis, housing stock, longevity, trends, urbanization, China

Les flux migratoires massifs des zones rurales vers les zones urbaines en Chine, conjugués à un déclin prévu de la population totale au cours des prochaines décennies, entraînent deux défis importants pour le logement en Chine : la croissance de son parc de logements urbains et la diminution des logements ruraux. Les systèmes de logements ruraux et urbains en Chine ont été analysés en utilisant un modèle d'analyse dynamique des flux de matériaux sur la période 1900-2100 appliqué à plusieurs scénarios supposant différentes voies de développement concernant la population, l'urbanisation, la demande de logements par habitant et la durée de vie des bâtiments. Les résultats de la simulation indiquent qu'il est probable que la construction de logements neufs diminuera pendant plusieurs décennies en raison de la croissance rapide des 30 dernières années et de l'accroissement prévu de la durée de vie des logements. Une telle oscillation de l'activité de construction de logements neufs aurait d'importantes implications pour l'industrie du bâtiment, l'emploi, la demande en matières premières et les émissions de gaz à effet de serre résultant de la production des matériaux de construction. Les choix politiques et pratiques qui permettraient d'en atténuer les effets négatifs sont envisagés.

Mots clés: parcs de bâtiments, demande de constructions neuves, analyse dynamique des flux de matériaux, parc de logements, durée de vie, tendances, urbanisation, Chine 


\section{Introduction}

Unprecedented urbanization is taking place in China. Since the adoption of reform and open-door policies in 1978, China's level of urbanization has risen from $18 \%$ in 1978 to $45 \%$ in 2007 (National Bureau of Statistics of China (NBSC), 1980-2008, 2005). It is expected that China will reach $55 \%$ urbanization by 2020 (Liu et al., 2003; Lan, 2008; Song and Ding, 2007). Fast-growing urbanization has been doubling China's building stock and partially the infrastructure stocks in the last 30 years (Kohler and Yang, 2007). Accompanying it, the rapid conversion of land from low-density agricultural to new urban zones of high density and material-intensive commercial and residential buildings has consumed enormous quantities of domestic and imported resources (Fernández, 2007). If the trend continues, China will inevitably face a shortage of domestic resource supplies (Shen et al., 2005) and exert pressure on global markets over the next two decades (Garnaut and Song, 2006). However, the relationship between the progress of urbanization in China and its demand of resources is not sufficiently understood. There is a need for a model to quantify the relationship. If this relationship could be understood, then it might be possible to make predictions for future resource demand.

Yang and Kohler (2008) analyzed Chinese building and infrastructure stock from 1978 to 2050 and calculated its material and energy implications during the ongoing urbanization process. Two different models are employed to do so: the period before 2005 is compressed in a static model for the reference year of 2005 , in which the age classes of the exiting stock are omitted; the period after 2005 employs a cohort approach, which allows for a more realistic analysis of ageing understood as the phasing out of individual cohorts with their characteristic material composition and energy use. This study provides plenty of valuable details about the composition of the Chinese built environment stock. However, the lack of a cohort approach for the existing building stock (due to a lack of existing reliable data) may be problematic because the rapid expansion of the Chinese building stock between 1978 and 2005 may have great material and energy implications for the coming decades. Further, the broad scope of the study (housing, nonhousing, infrastructure, etc.) and its wide modelling parameters (demolition and refurbishment rates of the exiting stock, lifespan and refurbishment interval of newly completed cohorts, etc.) creates difficulties with verifying the results and identifying which factor is more influential on the uncertainty. Nevertheless, the detailed historical analysis and carefully designed scenarios of this study form a good basis for future research.

In order to capture the essential relation between the urbanization process and its material consequences, the scope of the present research is on Chinese residential buildings, which has represented around $80 \%$ of the annual completed floor area in China over the last two to three decades (NBSC, 1980-2008, 2005). The research comprises two stages. The work presented here is the first stage. It aims to identify the long-term dynamics of the floor area in both the rural and the urban housing stocks in China, including the demand for new housing construction and obsolete housing demolition in rural and urban China during the urbanization process. The current authors anticipate the trends, identify the influential parameters, and discuss the uncertainties. The second stage of this research investigates the dynamics of housing-related construction material - iron and steel - which is presented by $\mathrm{Hu}$ et al. (2010b).

\section{Urbanization and housing in China}

Since 1958, the Chinese government has used the household registration system, called Hukou, to control the movement of people between rural and urban areas. This division led, among others, to a detachment between the rural and the urban housing systems, which are largely different in housing supply, renovation, and property transfer. In cities until 1978, urban housing was allocated by the Chinese government as part of social welfare for urban households (Zhu et al., 2000). During this period, around $75 \%$ of urban households were in the public rental housing sector (Huang, 2004). Since the rents were extremely low, ${ }^{1}$ urban public housing was heavily subsidized and created a heavy financial burden on the state (Shaw, 1997). Subsequently, insufficient state investment led to:

- a serious shortage of urban housing - per capita living space in cities declined from $4.5 \mathrm{~m}^{2}$ in the 1950 s to $3.6 \mathrm{~m}^{2}$ in 1978 (Center for Development Studies at the State Council, 1991)

- low-quality housing construction - especially during 1966-1971, ${ }^{2}$ when 'building housing by laying dry mud' was advocated from Beijing as a land-saving and high-speed measure, the result was a generation of low-quality, functionally defective dwellings (Beijing Municipal Chorography Compiling Council (BMCCC), 1999; Wu, 1989)

- inappropriate maintenance - as a result, housing ages quickly and its material quality has deteriorated (Shaw, 1997)

In the late 1970s, when China's economic reform started, previously suppressed housing problems initiated urban housing reform (Xu, 1993; Lee, 2000). This reform, with the aim of the marketization and privatization of urban housing production and 
consumption, triggered a strong wave of property (real estate) development in many major Chinese cities during the 1980s and 1990s (Zhu et al., 2000). By 2005 , only $8 \%$ of Chinese urban housing units were public rentals, and in the future most newly constructed owner-occupied housing will be in the private sector (Logan et al., 2010). With the move from 'welfare' housing to commodity housing, the provision of an adequate quantity and the quality of housing units in urban China began to be addressed successfully (Rapanos, 2002). However, this process is also accompanied by speculative investment. To curb soaring housing prices, since June 2006 China's central government has required that $70 \%$ of newly completed residential units must be smaller than $90 \mathrm{~m}^{2}$. From June 2009, central government further tightened financing for the purchase of second homes to cool the Chinese property market. Nevertheless, one positive effect of the privatization of housing seems undeniable, i.e. the lifetime expectancy of recently completed urban dwellings has largely increased. This is because:

- higher construction quality may have been achieved due to the expansion of housing construction for sale at market prices

- better maintenance of dwellings may be due to the owner-occupied housing

- the land-lease contract may support the expectation of urban households for using their purchased home for no less than 70 years $^{3}$

In rural areas, China's public housing provision had not been extended to the countryside (Zhang, 1997). Rural home building depended on privately accumulated savings and some pooled community labour (McKinley and Wang, 1992). Its quantity and quality are largely determined by the economic status of the peasants, which has improved significantly since 1978. Before 1978, the older stock of rural houses was often built of adobe walls and thatched roofs (McKinley and Wang, 1992). Chinese economic reforms started in the countryside in 1978. The implementation of a 'household production responsibility' system has substantially stimulated rural economic growth (Lin, 2007). When income increased, one of the first priorities for rural residents was to improve their housing. An extraordinary boom in rural house construction occurred in the 1980s. ${ }^{4}$ Between 1978 and 1988, rural per capita living space more than doubled, from about $8.1 \mathrm{~m}^{2}$ to $16.6 \mathrm{~m}^{2}$ (NBSC, 1999). The quality of rural housing also improved; many new houses were constructed of bricks, tiles, or reinforced concrete during the 1980s (McKinley and Wang, 1992).

Following the economic reforms from 1978, the substantial rise in agricultural productivity has generated a large surplus rural labour force that needs to be transferred into non-farm sectors and possibly into urban settlements. Responding to this challenge, since 1984 the Chinese government partially lifted the control over rural-urban migration (Lin, 2007). ${ }^{5}$ The massive level of rural-urban migration has then significantly raised the level of urbanization in China (Zhang, 2008), resulting in an expanding urban population and since 1995 a shrinking rural population (NBSC, 1980-2008, 2005). For resource management, this creates two important challenges: the growth of the urban housing stock acting as a sink of raw materials; and the shrinkage of the rural housing stock potentially becoming a source for secondary materials. In order to obtain a long-term vision of the challenges, this study aims to construct a robust physical base for future investigations about the relationship between urbanization in China and its material demand.

\section{Method}

The model developed in this study was based on a generic dynamic material flow analysis (MFA) model presented by Müller (2006) for simultaneously determining resource demand and waste generation through estimations of the population, its lifestyle, material intensity, and product lifetime. This approach has been applied for analyzing the stocks and flow dynamics of timber in Switzerland (Müller et al., 2004), floor area and materials in dwelling stocks (Müller, 2006; Bergsdal et al., 2007a), for projecting construction waste (Bergsdal et al., 2007b), and for modelling renovation activities of dwelling stock (Sartori et al., 2008). It was adopted by Brattebø et al. (2009) as the core of the generic model for exploring built environment metabolism. This approach tracks all vintage classes (year by year) individually and models the ageing of the housing stock based on the estimates of probability distribution functions for the lifetimes of all vintage classes, and so has special advantages for capturing long-term trends. The previous applications are all for industrialized countries, where standards of living are relatively homogenous among the total population. In the case of China, there are significant differences in housing between urban and rural areas. The current research extends Müller's generic dynamic MFA model to reflect the urban-rural relationship in China, with a distinction between urban and rural housing stocks (Figure 1).

\section{System definition}

The system for the Chinese dwelling stock is divided into two subsystems reflecting the urban and rural population and their housing stocks. The two subsystems are linked through migration flows from rural to urban areas $\left(m_{\mathrm{u}}\right)$, and vice versa $\left(m_{\mathrm{r}}\right)$. The conceptual 


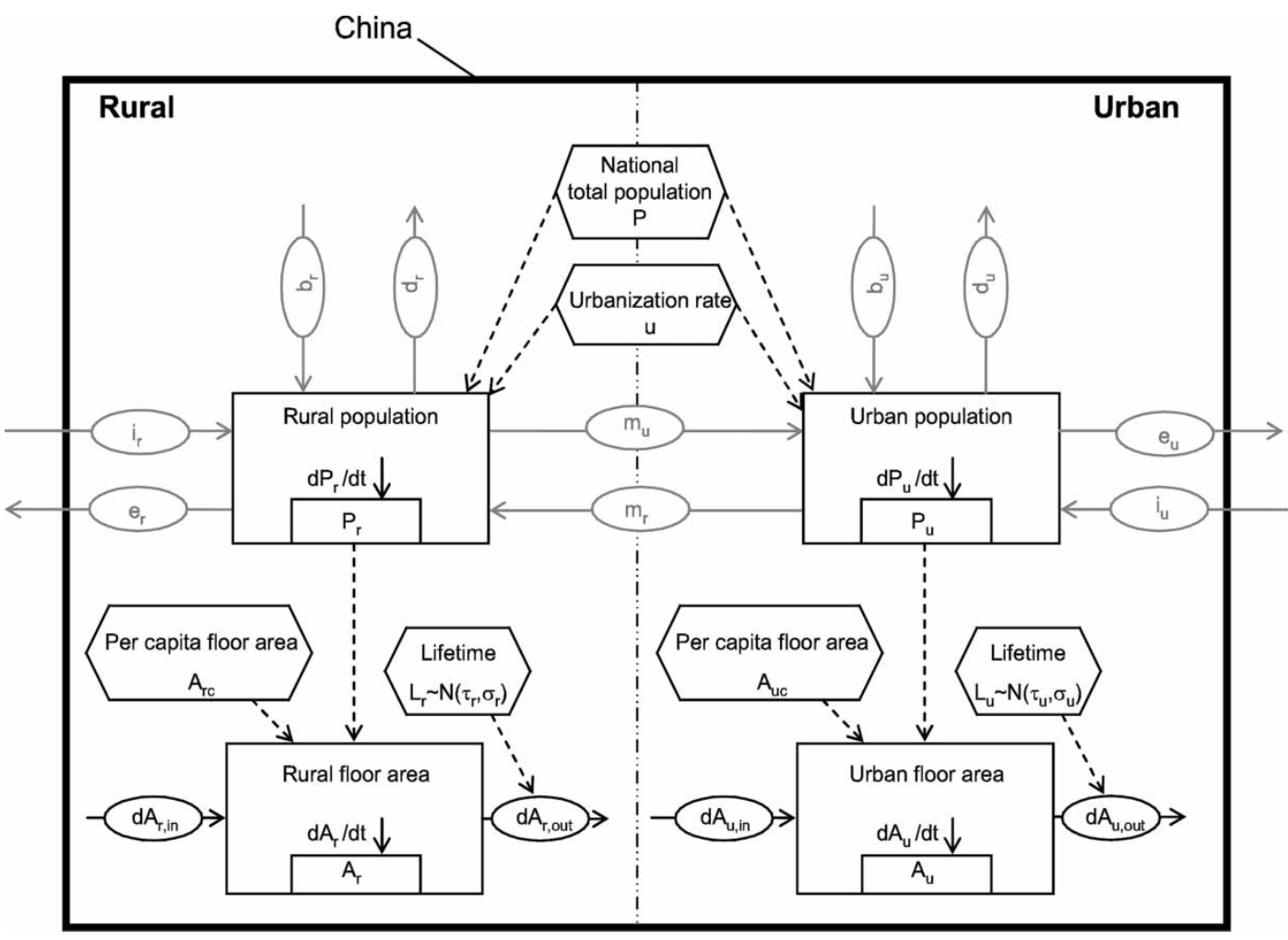

Figure 1 Conceptual outline of the stock dynamics model. Rectangles represent processes; ovals depict flows; hexagons illustrate determinants or drivers; and dashed lines represent influences between variables. Light grey depicts background flows not appearing in the modelling.

outline of the stock dynamics model (Figure 1) is developed from the generic dynamic MFA model presented by Müller (2006). Each subsystem involves two types of processes, illustrated with rectangles: the population within the region $(P)$ and the housing floor area of the region $(A)$. Both processes have a state variable $\left(P_{\mathrm{r}}, A_{\mathrm{r}}\right.$ for a rural area, or $P_{\mathrm{u}}, A_{\mathrm{u}}$ for an urban area) and a derivative, which is the net stock accumulation $\left(\mathrm{d} P_{\mathrm{r}} /\right.$ $\mathrm{d} t, \quad \mathrm{~d} A_{\mathrm{r}} / \mathrm{d} t$ or $\left.\mathrm{d} P_{\mathrm{u}} / \mathrm{d} t, \quad \mathrm{~d} A_{\mathrm{u}} / \mathrm{d} t\right)$. Each population process has three pairs of input and output flows, which are denoted, respectively, as: $b$ and $d$ for annual inflow and outflow of the population led by birth and death; $i$ and $e$ for annual immigration and emigration crossing China's border; and $m_{\mathrm{u}}$ and $m_{\mathrm{r}}$ for internal migration flows from rural to urban, and vice versa. The integrated effect of these flows on the share of people living in rural and urban areas can be indicated by the urbanization rate. In this study, the urbanization rate $(u)$ and the total national population $(P)$ are used as determinants for China's rural $\left(P_{\mathrm{r}}\right)$ and urban $\left(P_{\mathrm{u}}\right)$ population. The background flows $(b, d, i$, $\left.e, m_{\mathrm{u}}, m_{\mathrm{r}}\right)$ are not involved in modelling floor area dynamics, but used to calculate the net internal migration flow (see Appendix A) for the purpose of checking the consistence of the data sets with urbanization rates. Each housing floor area process has an input $\left(\mathrm{d} A_{\mathrm{r}, \text { in }}\right.$ or $\left.\mathrm{d} A_{\mathrm{u}, \text { in }}\right)$ and an output flows $\left(\mathrm{d} A_{\mathrm{r}, \text { out }}\right.$ or $\left.\mathrm{d} A_{\mathrm{u}, \text { out }}\right)$, represented with straight-line arrows and ovals. Housing floor area stocks and flows are shaped by determinants (hexagons) of per capita floor area $A_{\mathrm{rc}}$ or $A_{\mathrm{uc}}$; output flow is the delay of a past input, determined by lifetime function $L_{\mathrm{r}} \sim N\left(\sigma_{\mathrm{r}}, \tau_{\mathrm{r}}\right)$ or $L_{\mathrm{u}} \sim$ $N\left(\sigma_{\mathrm{u}}, \tau_{\mathrm{u}}\right)$; and the future input flow is formed to maintain the demanded size of in-use housing floor area stock for rural and urban, respectively.

\section{Mathematical model formulation}

The generic stock dynamics model developed by Müller (2006) is applied to both the urban and rural housing subsystems. The basic principle of the model is the law of mass conservation. Within either subsystem, the demand for dwelling stock in the region is driven by the corresponding population and living standard. Construction activity is determined by how much floor area has to be replaced because of demolition activity, plus any additional demand caused by increasing stock demand. Demolition activity is determined by past construction activity, with a delay of the service lifetime of the houses. A normal distribution function is assumed for the lifetime of all houses, though the mean and standard deviation of the function are estimated individually for rural and urban systems. The underlying equations are given in Appendix B; the six external parameters for the model are: 
$P \quad$ National total population

$u \quad$ Urbanization rate

$A_{\text {rc }} \quad$ Per capita floor area in rural region

$A_{\mathrm{uc}} \quad$ Per capita floor area in urban system

$L_{\mathrm{r}} \quad$ Lifetime distribution of rural housing $\left(L_{\mathrm{r}} \sim N\left(\tau_{\mathrm{r}}, \sigma_{\mathrm{r}}\right)\right)$

$L_{\mathrm{u}} \quad$ Lifetime distribution of urban housing $\left(L_{\mathrm{u}} \sim N\left(\tau_{\mathrm{u}}, \sigma_{\mathrm{u}}\right)\right)$

(a) national total population $(P)$

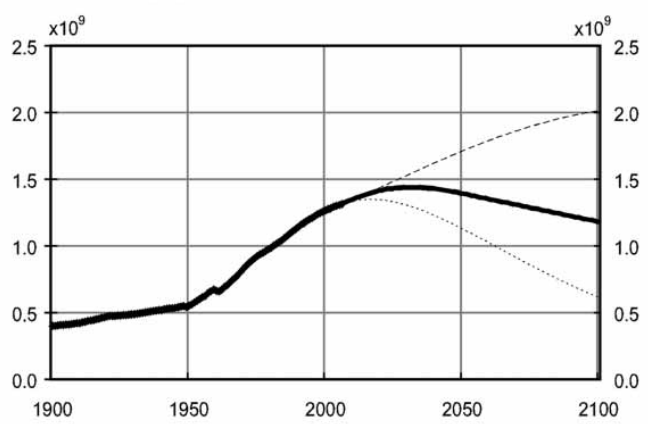

(c) per capita floor area in rural housing $\left(A_{\mathrm{rc}}\right)$

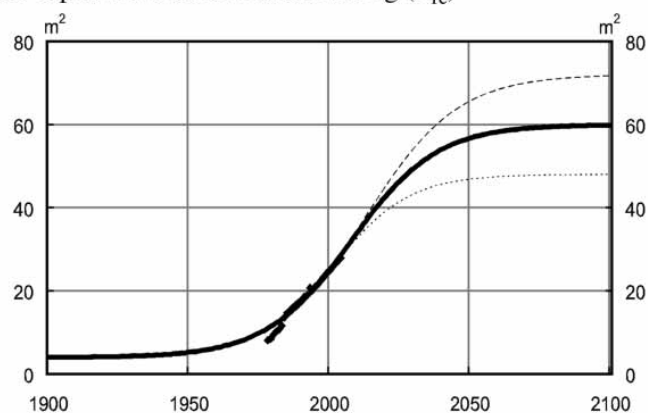

(e) average rural housing lifetime $\left(L_{\mathrm{r}}\right)$

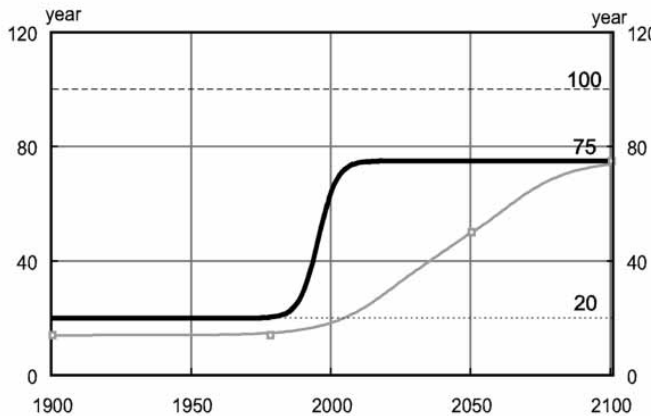

\section{Calibration}

The historical data from 1900 to around 2006 and the different projections for the period from 2006 to 2100 are input to calibrate the model (Figure 2). For each external parameter, a low, medium, and high variant are estimated for the future period. The variations in these future assumptions allow one to cover a wide range of possible development paths and to compare the influence of changes in one or a group of parameters on the entire system (see the section below on 'Sensitivity analysis').

Historical data on total national population, urbanization rate, ${ }^{6}$ and per capita floor area in rural and urban regions are collected from China Statistical

(b) urbanization rate $(u)$

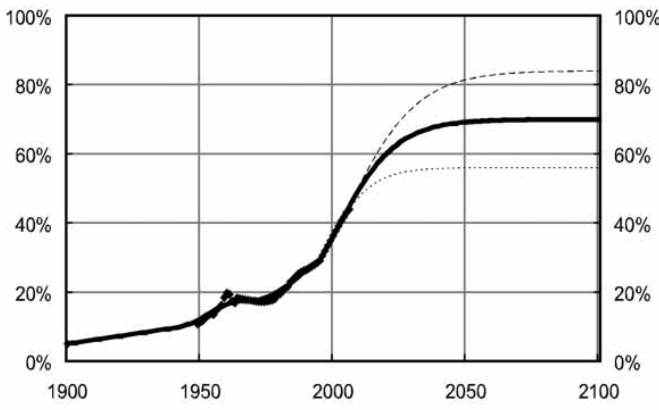

(d) per capita floor area in urban housing $\left(A_{\mathrm{uc}}\right)$

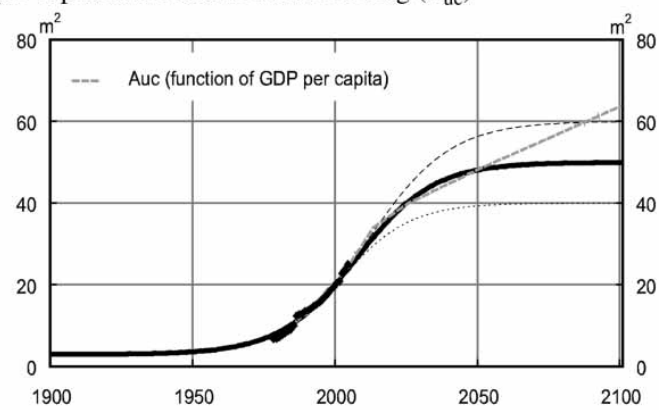

(f) average urban housing lifetime $\left(L_{\mathrm{u}}\right)$

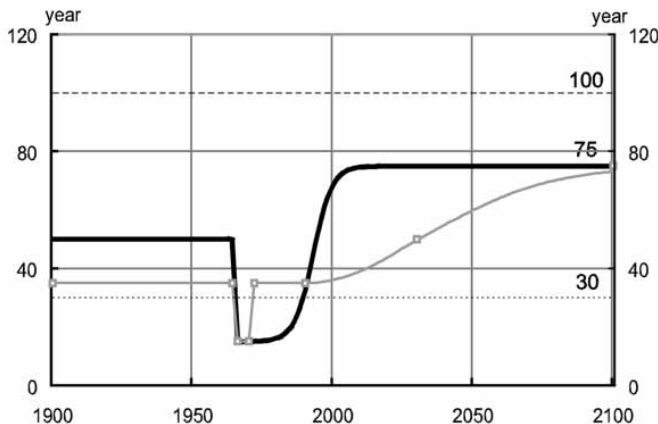

Figure 2 Calibration of input parameters, with historic data from 1900 to 2006, and estimation for variants low (dotted line), medium (bold solid line), and high (dashed line) from 2006 to 2100 . A dashed grey line represents the GDP-driving- $A_{\mathrm{uc}}$ scenario; a solid grey line represents gradually increasing lifetime scenarios. Black data points are empirical figures (National Bureau of Statistics of China (NBSC), 1980-2008, 2005). Grey data points are estimated lifetime values. 
Yearbooks (NBSC, 1980-2008, 2005) for 1949 to 2006. The total national population before 1949 was obtained from a database of the University of Utrecht (Ho, 1959; University of Utrecht, n.d.). The population projections are quoted from the low, medium, and high variants of China's population issued by the United Nations Population Division (UNPD, 2003, 2006, 2007). The urbanization rate in 1900 was assumed to be $5 \%$; and the yearly data between 1900 and 1949 were inserted by linear interpolation. The future urbanization rate was assumed to follow a logistic function to reach $70 \%$ by 2100 for the medium variant, and to reach $56 \%$ and $84 \%$ for low and high variants, respectively. Various previous forecasts for the future urbanization trend in China are illustrated in Appendix C for comparison. Data for per capita floor area in 1900 were assumed to be $4 \mathrm{~m}^{2}$ and $3 \mathrm{~m}^{2}$ per capita for residents in rural and urban areas, respectively. It was assumed that in future the figures would follow a logistic function to reach $60 \mathrm{~m}^{2}$ (a level the United States attained in the early 1990s; Guan et al., 2001) and $50 \mathrm{~m}^{2}$ (the current level in the Netherlands; Müller, 2006), in Chinese rural and urban areas by 2100 , for the medium scenario. The high and low variants in 2100 were set as $20 \%$ higher and $20 \%$ lower than the medium value, which are $72 \mathrm{~m}^{2}$ and $48 \mathrm{~m}^{2}$ for the rural area and $60 \mathrm{~m}^{2}$ and $40 \mathrm{~m}^{2}$ for the urban area, respectively. Considering the rapid economic development in China and the hypothesis that the wealthier people become, the more affluent living space they demand; the GDPdriving- $A_{\mathrm{uc}}$ scenario (where GDP is gross domestic product) is investigated for the purpose of comparison, in which urban per capita floor area is estimated as a function of China's per capita GDP (the dashed grey line in Figure 2(d)). The relation between per capita floor area and GDP per capita was identified by $\mathrm{Hu}$ et al. (2010a), and is presented in Appendix D.

The lifetime parameter is a crucial but poorly understood factor. A general view is that the average lifespan of Chinese existing buildings is rather short. Some Chinese experts estimated the real life time of the urban buildings constructed in the 1970s and 1980s to be only 30-40 years (Song, 2005), and for many rural houses to be not more than 15 years (Huang, 2006) due to their low quality (Zhao, 2003; Ye, 2003; Qu, 2003). However, since China's economic reform in 1978, the quality of Chinese new house construction has greatly improved, so this might positively influence the lifetime expectancy. In this study, a variable average lifetime is assumed for dwellings completed in different years for the medium scenario. A normal distribution is used to estimate the lifetime distribution of the dwellings erected at each year. The mean values of the lifetime functions are represented by the estimated average lifetime of dwellings, and the corresponding standard deviations are assumed to be $30 \%$ of the means.
Given the improving quality of housing since 1978, for the medium scenario it was assumed that by around 2020 the lifetime of newly completed dwellings, in both urban and rural China, would increase to 75 years, with reference to land lease for urban commercial housing (70 years). The transition of the lifetime expectancy from the historical low level to the future high level follows a double logistical function. Rural housing constructed before 1978 is estimated to have a short lifetime of 20 years (bold solid line, Figure $2(\mathrm{e})) .^{7}$ In cities, a lifespan of 50 years is estimated for dwellings built before 1966; and a lifespan of 15 year is assumed for the extremely bad quality cohort produced around 1966-1971 (bold solid line, Figure $2(\mathrm{f}))$. However, these assumptions are uncertain, because the available data do not allow for an analysis of the historical evolution of the dwelling longevity. In addition, the question of how long existing buildings can last depends on current and future decisions on maintenance, etc. To analyze the sensitivity of the lifetime parameter, a variance of average lifetime is chosen, assuming the constant values of 100 and 20 years as the high and low variants for rural dwellings, and 100 and 30 years for urban dwellings. Furthermore, to understand how influential the development pattern of the lifetime is, the gradually increasing lifetime scenario is investigated. For this scenario, it is assumed that, in the countryside, the lifetime of dwellings constructed before 1978 is 15 years (as estimated by Huang, 2006); but it gradually increases to 50 years (as Chinese national standard; Ministry of Construction of People's Republic of China (MCC), 2005) by 2050, and finally reaches 75 years by 2100 (solid grey line, Figure 2(e)). In cities (except for the 1966-1971 cohort with lifetime as 15 years), dwellings completed before 1978 are estimated to have a lifetime as 35 years (as in Yang and Kohler, 2008), and it is assumed they will gradually increase to 50 years by 2030 and reach 75 by 2100 (solid grey line, Figure 2(f)).

Using national total population $(P)$, urbanization rate $(u)$, and per capita floor area $\left(A_{\mathrm{rc}}, A_{\mathrm{uc}}\right)$ calibrated in Figure 2, the rural and urban stocks of the population and housing in China are calculated and the medium paths of the stocks are presented in Figure 3. For each of the floor area stocks, the highest and lowest variants are assembled. The product of high $P$, high $u$, and high $A_{\mathrm{uc}}$ is used as the high variant of floor area stock in urban housing, and that of low $P$, low $u$, and low $A_{\mathrm{uc}}$ is used for the low variant, as illustrated in the heading picture of Figure 5. While for rural housing, the product of high $P$, low $u$, and high $A_{\mathrm{ur}}$ is used as the high variant of floor area, and that of low $P$, high $u$, and low $A_{\text {ur }}$ is used for low variant, as illustrated in the heading picture of Figure 6. The low and high scenarios represent extreme paths for the future urban and rural housing stocks. They are then used for the sensitivity analysis in the next section. 

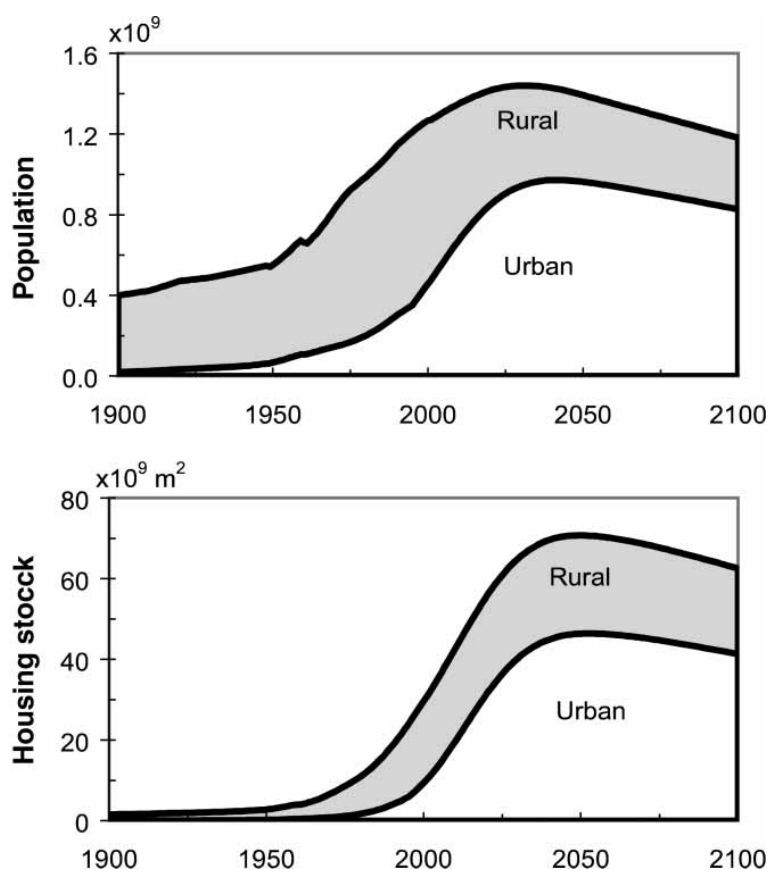

Figure 3 Population stocks and housing floor area stocks in rural (grey) and urban (white) China. All input parameters are set at medium values given in Figure 2 .

All the people shifting from the rural pool to the urban pool are considered as migration (Figure A1 in Appendix A). ${ }^{8}$ The forecast of the national population from UNPD's medium projection predicts that China's population will peak by 2030 . Combining this with the urbanization rate in the medium scenario for population, the rapidly increasing urban population in China will overtake the rural one some time between 2010 and 2015, and will peak around 2040. The rural population in China, which has already been shrinking since 1995, will keep declining in the first half of the 21st century. It indicates that China has experienced the biggest internal migration period since 1996 with a figure of over 15 million migrants per year over the period of a decade. The combined result of the total national population growth and the urbanization trend predicts a steady decrease of the internal migration till the end of 2050, and around 300 million people in China will by then have shifted their lifestyle from rural to urban.

\section{Validation}

The model was validated using historical data from newly completed residential buildings in rural and urban China, which are available in the Statistical Yearbooks for 1984-2006 (Figures 5(c), 5(d) and 6(c), 6(d)). The validation shows that the medium scenario results fit with the climbing trend of urban housing construction. However, the modelling values tend to be higher than the statistical values. This could indicate an underestimation of the lifetime or an inconsistency in the official statistics for population, housing stock, and construction activities. For urban areas, a third reason may be the fraction of 'urbanization' resulting from the transition from rural to urban areas. According to Yang and Hui (2008), during 2001-2006, about 18-20 million people shifted from rural to urban stock annually, among which nearly 5 million per year are due to official designation of new cities without really moving and do not require housing from urban stock. It means about $30 \%$ of annual rural-urban migration should be subtracted from the urban population stock when calculating the demand for new urban housing construction. This factor has been considered in this study and the adjusted result for the medium scenario is presented in Figure 5(d) (dotted grey line). As the rural-urban migration is expected to decrease through to 2050, its effect on overestimation also decreases over time. This adjustment amends the overestimated peak construction demand. However, it does not affect the projected pattern of oscillation in Chinese demand for urban housing construction.

For rural areas, the results correctly reflect the trend of declining rural housing construction. Compared with the statistical data, the model seems also to overestimate the rural housing construction. This might be attributed to poor statistics, considering that rural houses are mainly built by individual farmers and are not monitored as much by government. Moreover, according to the historical data, there was a higher peak of rural new housing construction in 1986 and another lower peak in 1995. However, there is only one peak appearing in about 1995 in the simulation results. The reason for the delayed peak could be an underestimate of the lifetime of rural houses built in the past. The difference in the shape reflects that the power of this model is limited to capturing shortterm fluctuations. Nevertheless, one should be aware that a stock dynamics prediction is designed for viewing the long-term trend. In order to capture the essential long-term behaviour, some short-term fluctuations are treated as noise and removed during smoothing of the input data.

\section{Stocks and flows of housing in China}

This section presents the simulation results for stocks and flows of urban and rural housing in China. The base case scenario is defined as the alternative applying the medium values for all input parameters. The results are shown in Figure 4.

\section{Medium scenario results}

The medium scenario for the rural housing system (Figure 4(a)) assumes a saturated housing stock 

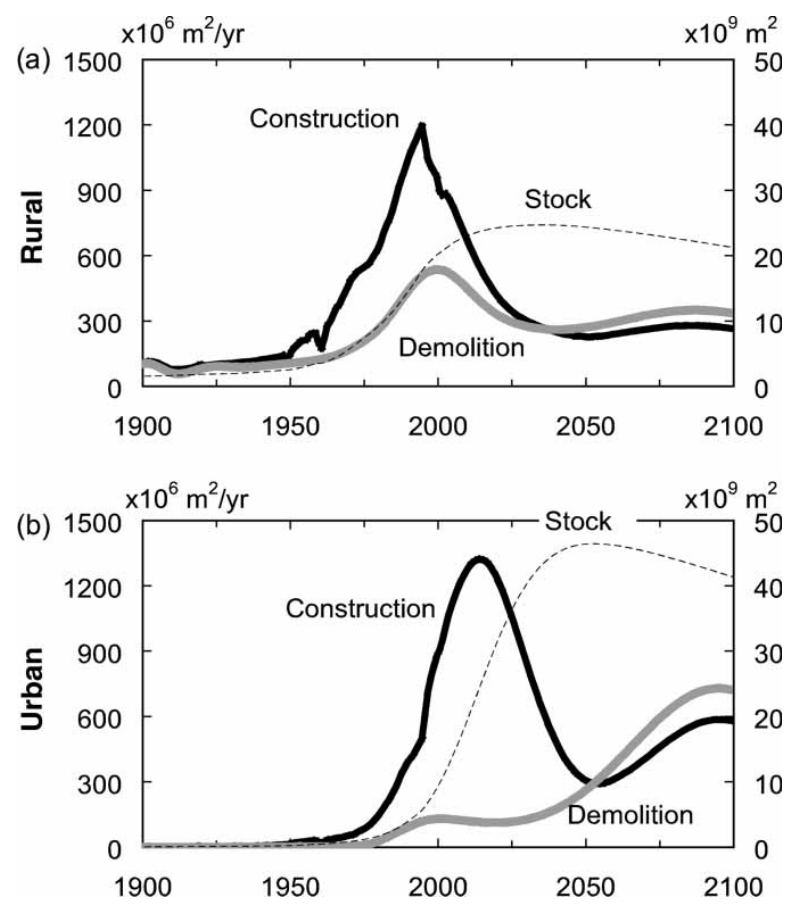

Figure 4 Simulation results for housing stocks and flows in rural and urban China. Stocks are measured on the right axis, and flows on the left. All input parameters are set at medium values given in Figure 2.

around 2025 as the combined result of the declining rural population (Figure 3(a)) and the increasing per capita housing space (Figure 2(c)) in rural China. A strong oscillation was found in new construction demand for the rural housing system, from 1.2 billion to 0.2 billion $\mathrm{m}^{2}$, which is about a factor of six of the peak of new construction. This significant drop started about a decade ago and will reach its lowest level around 2050 and stay at roughly this low level through the end of the current century. Due to the short lifetime estimation (20 years before 1978), the demolition activity has already peaked around 2000 . Currently, there are more demolition activities in rural than in urban areas, but the rural rate is shrinking, while the urban rate is increasing after 2030 and will overtake the rural one in the second half of this century.

The medium scenario for the urban housing system (Figure 4(b)) assumes a saturated housing stock around 2050 due to the saturated urban population (Figure 3(a)) and the stabilized per capita floor area (Figure 2(d)). The demolition activity started climbing around 1975 because of the replacement of the lowquality dwellings constructed during 1966-1971, and it has stabilized at the current level since about 1995. The demolition activity will stay more or less at the same level by 2030, and will rise only at the beginning of the second half of the century, when the houses built during the first building surge will start being retired. Rapid urbanization and the fast- improving living standard of urban habitants have led to the accelerated growth of housing construction in the last decades. The medium scenario indicates that new construction activity will reach a peak of 1.3 billion $\mathrm{m}^{2}$ around 2011; subsequently, new construction declines for about 40-50 years to 0.3 billion $\mathrm{m}^{2}$ /year, which is about one-quarter of the peak of new construction. This peak, which marks the time when the stock growth starts to slow down (inflection point), can be expected to arrive very soon in the near future, if it has not arrived already. The oscillation is a consequence of the past fast growth: the build-up time of the housing stock (approximately 30 years) is shorter than the expected lifetime of the buildings. The first rise of new construction is caused by the growth in stock demand, and when the saturation of the stock occurs, the demand for new construction will be due to replacement reasons only. Because of the expected lengthening lifetime of buildings since 1978, the demand for replacement will commence only after 2050 , and a period of low demand for new construction emerges and the oscillation occurs.

\section{Sensitivity analysis}

The simulation results from the previous section are based on the medium variant for all parameters. As there are significant uncertainties regarding how these determinants will behave in the future, more simulations are performed to analyze the relative importance and influence of the parameters of floor area stock and housing lifetime for the variants assembled and described in the section 'Calibration', while other parameters are at medium levels. The extreme values of the determinants on housing stock and the average dwelling lifetime are investigated. Meanwhile, to understand the influence of the development patterns of the parameters, the scenarios GDP-driving- $A_{\mathrm{uc}}$ and gradually increasing lifetime are examined. Quantification of the input parameters is presented in Figure 2. Results of the sensitivity analysis are illustrated in Figures 5 and 6 for urban and rural housing systems, respectively.

The sensitivity analysis for floor area stock in urban area shows that:

- The impact of floor area stock to demolition activity will be very small for the next couple of decades. However, it will have a considerable impact for a long time after 2050 and to the end of this century because the demolition activity comes one lifetime delay after the new construction.

- The oscillation phenomenon in new construction is independent of stock scenarios, and increasing or decreasing the overall floor area stock will not affect the oscillations within the projection period. However, relatively speaking, the larger the future housing stock, the less dramatic the 

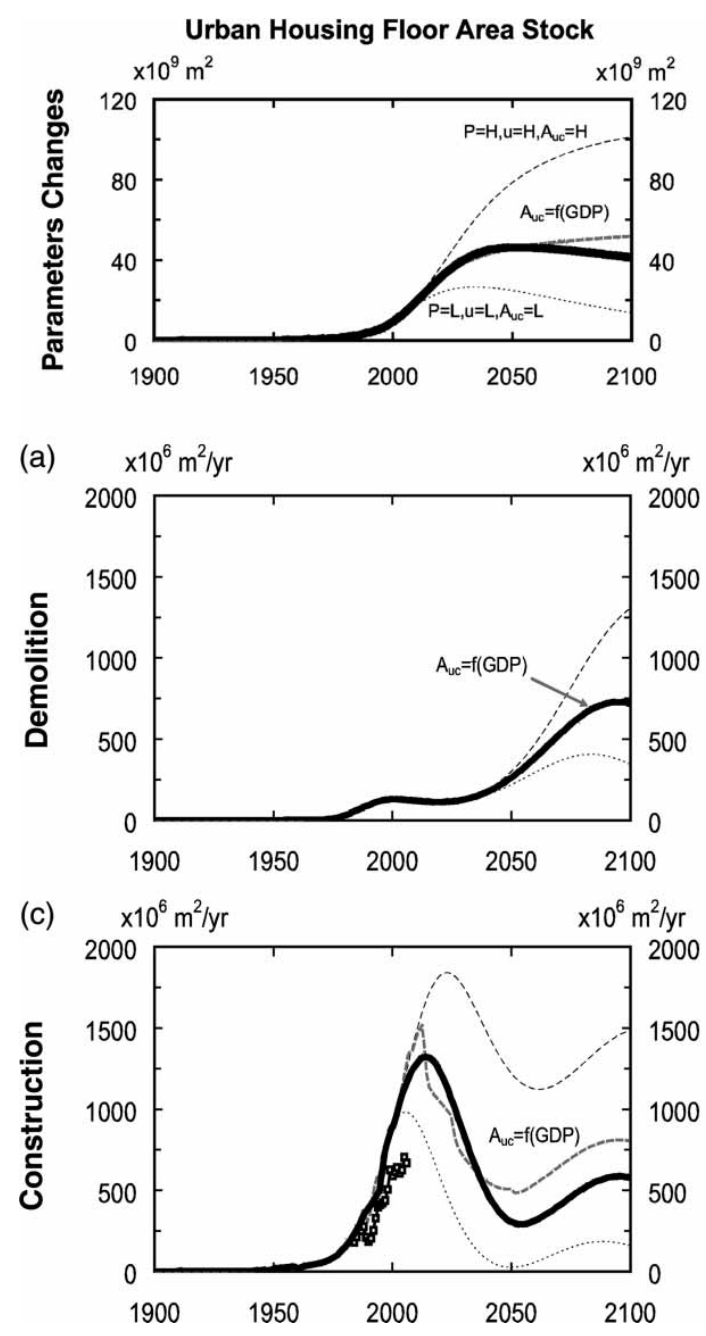

Urban Housing Lifetime

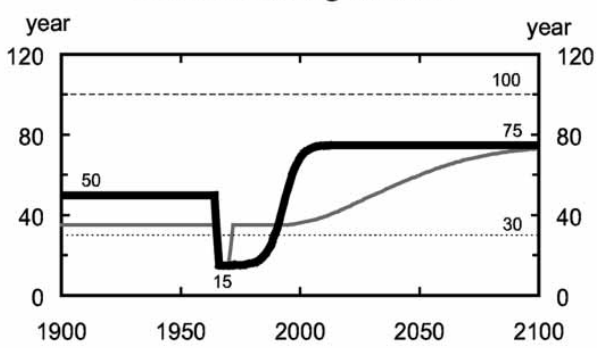

(b) $\times 10^{6} \mathrm{~m}^{2} / \mathrm{yr}$

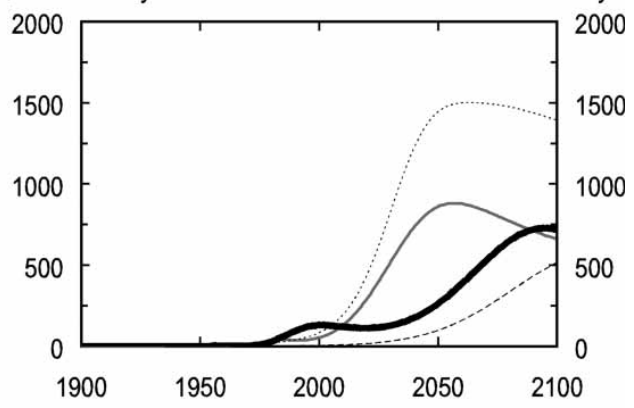

(d) $x 10^{6} \mathrm{~m}^{2} / \mathrm{yr}$

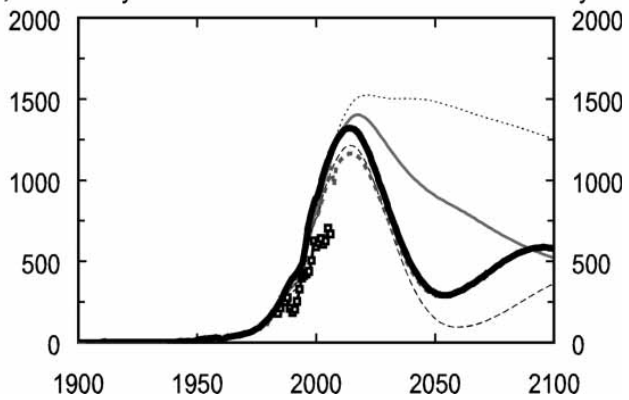

Figure 5 Sensitivity analysis for the urban housing system. Outflow (demolition) and inflow (construction) ( $\mathrm{m}^{2} /$ year) are influenced by floor area stock and lifetime variants low (dotted line), medium (bold solid line), and high (dashed line). A dashed grey line represents the GDPdriving- $A_{\mathrm{uc}}$ scenario; a solid grey line represents a gradually increasing lifetime scenario; and a dotted grey line denotes medium scenario results adjusted by rural-urban land transition. Data points in the bottom two figures are empirical figures of annually completed residential floor areas in urban China (National Bureau of Statistics of China (NBSC), 1980-2008, 2005). H, high variant; L, low variant.

oscillations will be. If the stock growth is prolonged, the peak can be delayed in time, but the decline cannot be avoided.

- If the level of China's urban per capita floor area is largely determined by its GDP development, China is at an even sharper downwards turning point in its demand for new urban housing construction.

- If the macro-control measures of the Chinese government (e.g. $70 \%$ of new constructed housing units are required to be smaller than $90 \mathrm{~m}^{2}$ and financing for second homes is tightened as a discouragement of second home purchases) slow the increased pace of its urban per capita floor area, a lower recent peak level is expected, followed by an even deeper drop in the demand for urban housing construction until 2050.
The sensitivity analysis for housing lifetime in urban areas shows that:

- The oscillation in new construction is mainly dependent on the lifetime of the buildings. The longer the lifetime of the buildings, the stronger the oscillation will be. For the extremely short lifetime scenario, almost no oscillation is observed in the simulation result. A better understanding of building lifetimes is, therefore, essential for forecasting future construction and demolition activities.

- If the existing urban dwellings in China have a short lifespan of 30 years, and if this situation were to continue throughout the 21st century, China may not encounter oscillation in urban housing construction. However, its continuous high construction level will be accompanied by a 

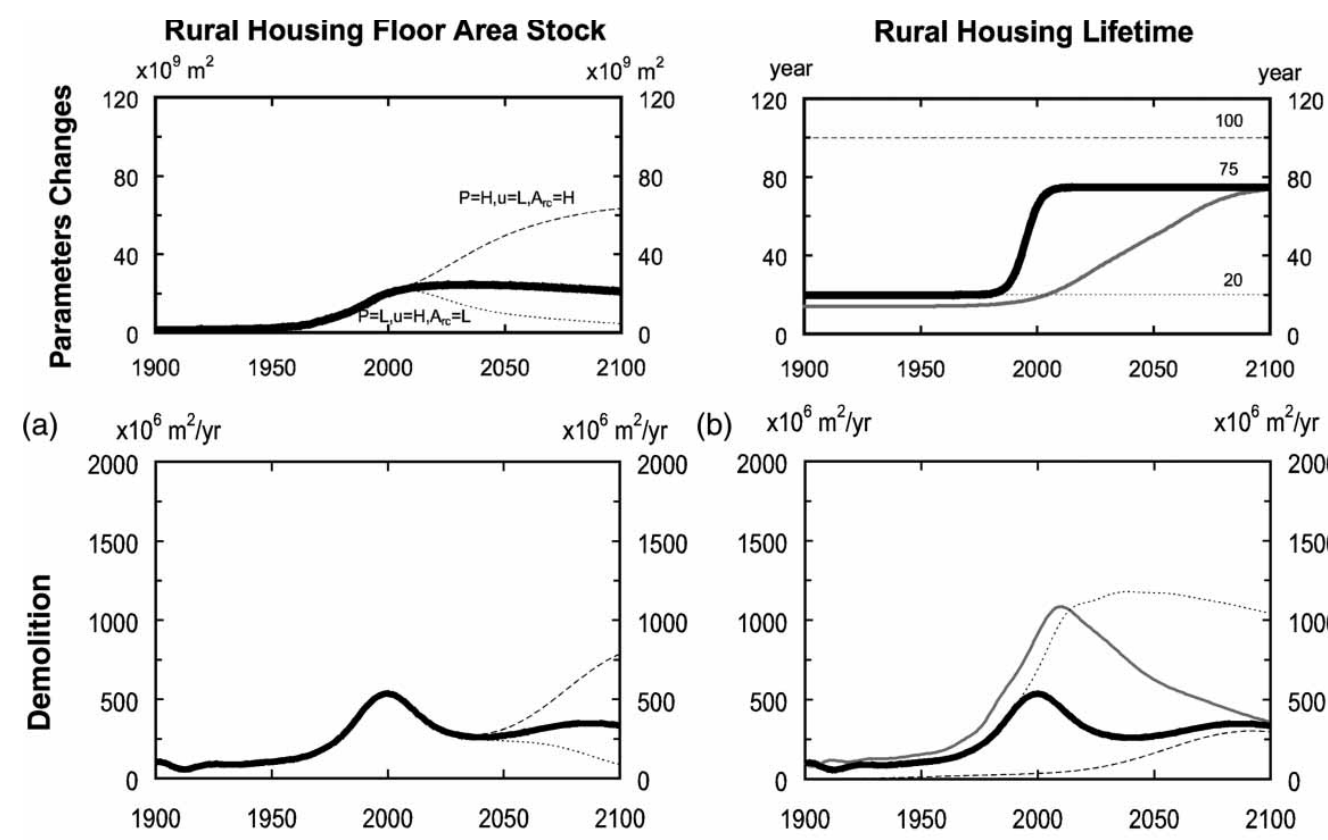

(b) $\times 10^{6} \mathrm{~m}^{2} / \mathrm{yr}$
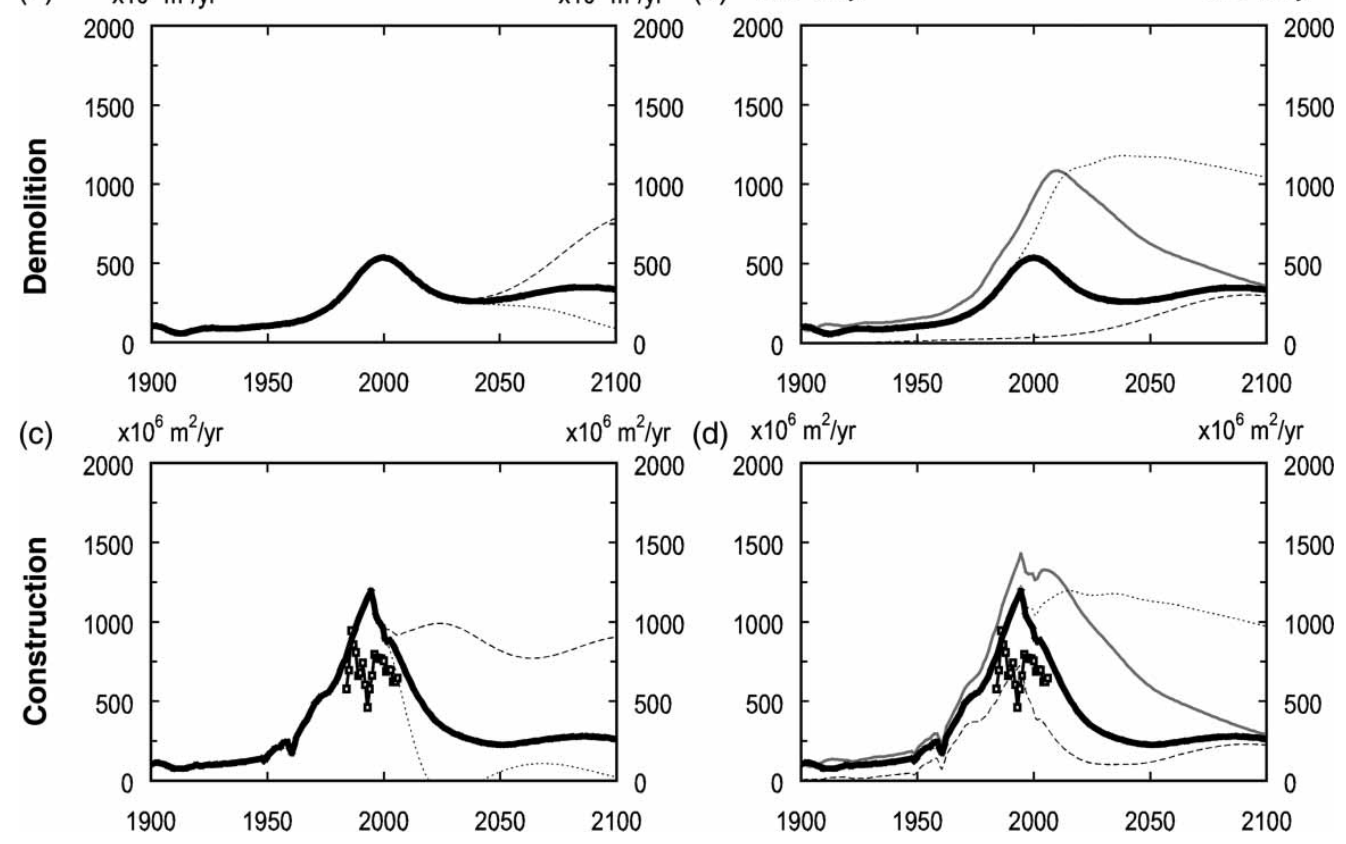

Figure 6 Sensitivity analysis for the rural housing system. Outflow (demolition) and inflow (construction) ( $\mathrm{m}^{2} /$ year) are influenced by floor area stock and lifetime variants low (dotted line), medium (bold solid line), and high (dashed line). A solid grey line represents a gradually increasing lifetime scenario. Data points in the bottom two figures are empirical figures of annually completed residential floor areas in rural China (National Bureau of Statistics of China (NBSC), 1980-2008, 2005). H, high variant; L, low variant.

dramatic rise in the level of demolition. This would be problematic in terms of resource supply and waste management.

- If the lifespan of Chinese urban dwellings gradually increases over the 21st century, a less steep but continuous decrease may be expected in China's urban residential construction from a few years later till the end of this century.

- If the rural-urban land transition is considered, and the effect that about $30 \%$ of annual rural-urban migration (calculated according to Chinese urbanization development) does not demand new urban housing construction is adjusted, the simulated peak value of construction demand can be $20 \%$ lower, but the strong oscillation pattern remains.

It is important to remember that the results presented here reflect a national aggregate. Since construction activity varies greatly between different regions, it is expected that the oscillation might be much more severe in some areas than in others. The effect will be particularly strong for the small new cities or towns built up in a very short time in the rapid urbanization progress.

The sensitivity analysis for rural housing floor area stock shows that:

- For demolition activity there is no impact of stock scenarios for the next couple of decades, but in the long run the impacts will be larger.

- Construction activity strongly depends on future demand of the floor area stock. For the saturation and shrinking stock scenarios, strong oscillations will occur due to the delayed demand for replacements, while in the growing stock scenario the oscillation is damped because the new construction 
has to meet the demand not only for replacement, but also for increasing stock.

The sensitivity analysis for rural housing lifetime shows that:

- The shorter the lifetime of the buildings, the higher the construction and demolition activity level will be. For the constantly short lifetime scenario $(20$ years), the demolition level might climb to be more than double the peak estimated by the medium scenario and stay at the high level throughout the 21st century. However, the constantly short lifetime scenario seems not to be supported by historic construction figures (Figure 6(d)) which show a general declining trend since late 1980s. Instead, the statistic data seem support a middle path between the medium and high lifetime scenarios.

- If the extremely short lifespan of the existing rural housing of 15 years (as estimated by some Chinese experts) increases slowly to 75 years by year 2100, the demolition demand in Chinese rural housing may be right at the peak. The peak value can be more than double of the medium scenario results. However, the available data do not allow for a judgement to be made of how high the real demolition level in the Chinese countryside actually is. The increasing numbers of 'hollow villages' 9 in recent years suggest that there is a growing number of abandoned rural houses. Both the gradually increasing lifetime and the medium scenarios suggest that the current high demolition demand in Chinese rural housing is likely to decrease over the next few decades.

- Driven by the estimated higher replacement demand, a gradually increasing lifetime scenario projects a higher current construction demand than the medium scenario, but a similar reduction trend in the long-term. The gradually increasing scenario seems to have captured the two rural construction peaks in history, but it overestimated the construction level even more seriously, indicating a probable underestimation of dwelling lifespan.

- If an extremely short lifetime would not be the case for the newly constructed rural houses, how many people would like to live in the countryside seems more relevant for projecting Chinese future demand in rural residential construction.

\section{Discussion}

\section{Limitations of the model}

The model used in this study is a simplified physical accounting causal model with limitations, and with uncertainties only partially covered by scenario analysis. When interpreting its results, there are several concerns. First, this model is suitable for projecting longterm trends, but it is not precise for short-term dynamics. As shown in the validation, the model correctly reflects the general long-term trend, but overestimates the recent new construction level in urban areas. One reason for this overestimation could be that the model neglects the rural-urban land transition in China's urbanization. As mentioned previously, a significant number of people who become classified as 'urban' do not really move, thus there is no additional demand for urban housing construction. Adjusted results show that the model overestimates the recent peak value in urban housing construction by nearly $20 \%$. However, the pattern of oscillation in construction demand holds, even after this adjustment. Second, the analysis results of the model are not rigid predictions; they are feasible scenarios the logical consequences of the potential paths of the future population's demand for housing floor area and the lifespan of dwellings. The model states that if the Chinese urban dwellings completed from the 1980s will last for more than 30 years, China's demand for new housing construction will soon enter a downward trend. But it cannot answer whether the lifespan of Chinese urban dwellings has been or will be prolonged. The lifespan is determined exogenously. A better understanding of the lifespan of existing buildings and further observations of the evolution trend of this parameter will increase the precision of this model projection. Nevertheless, the wide variance of lifespan scenarios investigated in this study seems to indicate the robustness of the results.

\section{Implications of the oscillation}

The oscillation in urban housing construction has at least two impacts: less construction material demand and fewer construction activities. The impact of less material demand is commendable. From a resource preservation point of view, the decreasing material demand implies that urbanization in China should not raise the problem of material scarcity in housing construction. However, the impact of fewer construction activities could be problematic:

- if the oscillation phenomenon were apply to the whole construction sector, then a potential unemployment problem might be foreseen

- less new construction implies less effective building performance as older buildings are not built to the current building regulations

- residential construction is one of the biggest users of steel in China; the expected construction reduction may adversely affect the steel industry (Hu et al., 2010b) 


\section{Options to dampen the oscillation}

The expected oscillation in construction demand may affect the stability of the construction industry, and its upstream material suppliers. According to this study, there are basically two types of strategies to mitigate the oscillation. One is to encourage high floor area demand in the future. This option may delay the problem and lead to high construction material input, but it will not diminish the oscillation. The macro-control policy of the Chinese government on housing production structure and second home purchases does not support this high floor area scenario. Nor does this option appear to be realistic.

Another choice is to continue the current short lifespan situation of the buildings. This option may dampen the oscillation in construction, at the expense of significantly increasing demolition waste and resource demand. But it also offers the chance to replace some poorly performing buildings and provides the possibility of recycling secondary resources from demolition and replacing primary resource use. Would this be a feasible option for China to progress to a sustainable construction sector? Further research is needed to explore the trade-offs between recycling and durability. The model presented in this study provides a framework for future investigations.

\section{Conclusions}

This study is a first attempt to analyze the long-term dynamics of the Chinese housing stocks by using a vintage approach for urban and rural dwelling inventories. By using population, per capita floor area, and dwelling lifetime as the main drivers, this approach allows for a simultaneous forecast of both construction and demolition rates. Several scenarios are generated and compared with a base medium scenario for a better understanding of future projections. The main findings are:

- In the urban housing system, almost all scenarios show a declining construction activity for the coming decade, except if the average dwelling lifetime is below about 30 years and the demand for replacement will kick-in to counter the declining demand for stock expansion.

- In the rural housing system, demand for new construction has already been decreasing since the last decade. The levels of future construction activity will largely depend on the pace of urbanization, if the extremely short lifetime of about 20 years in the future will not be the case, as the current statistic data suggest.

- Demolition activity depends largely on the lifetime assumption of existing buildings. The general trend is that the demolition level will rise in cities sooner or later over the 21st century, while it has probably already reached the top in the countryside. A high but decreasing demolition level may be expected in the countryside for the next few decades. Given the significant magnitude of the current rural demolition level, it seems worthwhile to have a more detailed review of the potential for recycling materials from the Chinese rural housing stock.

- The lifetime distribution of dwellings is one of the most influential factors determining future construction and demolition levels. A better understanding of the lifetime expectancy of Chinese housing stocks will improve the projection power of this model.

\section{Acknowledgements}

This work was supported in part by the Asia-Link project 'Human Resources Development for the Improvement and Protection of Environment in Asia (ProtEA)' of European Union (Number CN/ASIA-LINK (110744)); and by the China Exchange Programme 'Innovative Methodologies for Sustainable Waste Management (InnoMan)' of the Dutch Academy of Art and Science (Number 09CDP009). The authors would like to thank Helge Brattebø for his kind suggestions. The authors also wish to thank the three BRI referees and the Editor for their very useful comments and suggestions.

\section{Reference}

Beijing Municipal Chorography Compiling Council (BMCCC) (1999) Volumes: Architecture Chorography, BMCCC, Beijing. [in Chinese].

Bergsdal, H., Brattebø, H., Bohne, R.A. and Müller, D.B. (2007a) Dynamic material flow analysis for Norway's dwelling stock. Building Research \& Information, 35(5), 557-570.

Bergsdal, H., Bohne, R.A. and Brattebø, H. (2007b) Projection of construction and demolition waste in Norway. Journal of Industrial Ecology, 11(3), 27-39.

Brattebø, H., Bergsdal, H., Sandberg, N.H., Hammervold, J. and Müller, D.B. (2009) Exploring built environment stock metabolism and sustainability by systems analysis approaches. Building Research \& Information, 37(5), 569-582.

Center for Development Studies at the State Council (1991) China Economic Yearbook, Economic Management Press, Beijing.

Chan, K.W. and Hu, Y. (2003) Urbanization in China in the 1990s: new definition, different series, and revised trends. China Review, 3(2), 49-71.

Eurostat (European statistics) (2009) (available at: http://epp. eurostat.ec.europa.eu/).

Fernández, J.E. (2007) Resource consumption of new urban construction in China. Journal of Industrial Ecology, 11(2), 99-115.

Garnaut, R. and Song, L. (2006) China's resources demand at the turning point, in R. Garnaut, L. Song (eds.): The Turning Point in China's Economic Development, Asia Pacific Press, Canberra, ACT, pp. 276-293.

Guan, K., Feng, K. and Zeng, S.X. (2001) Urban housing reform and development in China. Building Research \& Information, 29(4), 286-292. 
Guest, R.S. and McDonald, I.M. (2007) Global GDP shares in the 21st century - an equilibrium approach. Economic Modelling, 24, 859-877.

Hashimoto, S., Tanikawa, H. and Moriguchi, Y. (2007) Where will large amounts of materials accumulated within the economy go? - a material flow analysis of construction minerals for Japan. Waste Management, 27, 1725-1738.

Ho, P.-T. (1959) Studies on the Population of China, 1368 1953, Harvard University Press, Cambridge, MA.

Hu, M., Pauliuk, S., Wang, T., Huppes, G., van der Voet, E. and Müller, D.B. (forthcoming 2010b) Iron and steel in Chinese residential buildings. Resources, Conservation \& Recycling, DOI: 10.1016/i.resconrec.2009.10.016.

Hu, M., van der Voet, E. and Huppes, G. (forthcoming 2010a) Dynamic material flow analysis for strategic construction and demolition waste management in Beijing. Journal of Industrial Ecology.

Huang, W. (2006) Speech given at the meeting of 'Building New Countryside of the Socialist Society', Beijing, China, 21 March 2006, Ministry of Construction of China, Beijing (available at http://www.cin.gov.cn/ldjh/jsld/200612/ t20061225_37469.htm). [in Chinese].

Huang, Y.Q. (2004) The road to homeownership: a longitudinal analysis of tenure transition in urban China (1949-94). International Journal of Urban and Regional Research, 28, 774-795.

Kohler, N. and Yang, W. (2007) Long-term management of building stock. Building Research \& Information, 35(4), 351-362.

Komatsu, Y., Kato, Y. and Yashiro, T. (1994) Survey on the life of buildings in Japan, in CIB W70 Symposium, Tokyo, Japan, Vol. 1, pp. 111-118 (available at: http://www.f. waseda.jp/ykom/CIB94.pdf)

Lan, X. (2008) Decoding China's urbanization. Beijing Review (available at: http://www.bjreview.com/print/txt/200807/05/content_132142.htm).

Lee, J. (2000) From welfare housing to home ownership: the dilemma of China's housing reform. Housing Studies, 15(1), 61-76.

Lin, G. (2007) Reproducing spaces of Chinese urbanization: new city-based and land-centred urban transformation. Urban Studies, 44(9), 1827-1855.

Liu, S., Li, X. and Zhang, M. (2003) Interim Report: Scenario Analysis on Urbanization and Rural-Urban Migration in China, International Institute for Applied Systems Analysis, Laxenburg (available at: http://www.iiasa.ac.at/Admin/ PUB/Documents/IR-03-036.pdf).

Logan, J.R., Fang, Y. and Zhang, Z. (2010) The winners in China's urban housing reform. Housing Studies, 25(1), 101-117.

McKinley, T. and Wang, L. (1992) Housing and wealth in rural China. China Economic Review, 3(2), 195-211.

Ministry of Construction of People's Republic of China (MCC) (2005) Code for Design of Civil Buildings (GB503522005), China Planning Press, Beijing.

Müller, D.B. (2006) Stock dynamics for forecasting material flows - case study for housing in the Netherlands. Ecological Economics, 59, 142-156.

Müller, D.B., Bader, H.P. and Baccini, P. (2004) Long-term coordination of timber production and consumption using a dynamic material and energy flow analysis. Journal of Industrial Ecology, 8(3), 65-87.

National Bureau of Statistics of China (NBSC) (2005) Statistical Compendium of China 1949-2004, China Statistical Press, Beijing.

National Bureau of Statistics of China (NBSC) (various years, 1980-2008) China Statistical Yearbook 1980 ... 2008, China Statistical Press, Beijing.

Qu, T. (2003) Enhance rural housing planning and promote urbanization construction. Shanghai Rural Economy, no. 9, 26-27. [in Chinese].

Rapanos, D. (2002) Modern urban housing in China. Building Research \& Information, 30(3), 215-218.

Sartori, I., Bergsdal, H., Müller, D.B. and Brattebø, H. (2008) Toward modeling of construction, renovation and demolition activities: Norway's dwelling stock, 19002100. Building Research \& Information, 36(5), 412-425.

Shaw, V.N. (1997) Urban housing reform in China. Habitat International, 21(2), 199-212.

Shen, L., Cheng, S., Gunson, A.J. and Wan, H. (2005) Urbanization, sustainability and the utilization of energy and mineral resources in China. Cities, 22(4), 287-302.

Song, Ch.H. (2005) Whole life and highgrade quality-stick to the implement housing performance certification. Housing Science, 290(8), 287-302.

Song, Y. and Ding, C. (eds) (2007) Urbanization in China: Critical Issues in an Era of Rapid Growth, Lincoln Institute of Land Policy, Cambridge.

The World Bank (2008) UN Common Database, The World Bank, Washington, DC (available at: http://unstats.un. $\operatorname{org} /)$.

United Nations Population Division (UNPD) (2003) World Population in 2300, Draft of 9 December 2003, United Nations, New York, NY.

United Nations Population Division (UNPD) (2006) World Population Prospects: The 2006 Revision, United Nations, New York, NY (available at: http://esa.un.org/unpp).

United Nations Population Division (UNPD) (2007) World Urbanization Prospects: The 2007 Revision, United Nations, New York, NY (available at: http://esa.un.org/ unup).

University of Utrecht (n.d) Database (available at: http://www. library.uu.nl/wesp/populstat/Asia/chinac.htm).

Wang, Y. and Murie, A. (1999) Housing Policy and Practice in China, Macmillan, New York, NY.

Wu, C. (1989) Forty years of housing construction in Beijing. City Planning, 5, 13-17.

Xu, X.Y. (1993) Policy evaluation in China's housing reform. Evaluation and Program Planning, 16, 39-47.

Yang, H. and Hui, J. (2008) Forecasting housing supply and demand in China for next five years. Shanghai Real Estate, July, 26-30. [in Chinese].

Yang, W. and Kohler, N. (2008) Simulation of the evolution of the Chinese building and infrastructure stock. Building Research \& Information, 36(1), 1-19.

Ye, M. (2003) Problems and strategies of China's rural housing industrialization. Information of China Construction, 12, 31-33. [in Chinese].

Zhang, L. (2008) Conceptualizing China's urbanization under reforms. Habitat International, 32, 452-470.

Zhang, X.Q. (1997) Chinese housing policy 1949-1978: the development of a welfare system. Planning Perspectives, 12(4), 433-455.

Zhao, Z. (2003) Dualistic system of rural and urban housing in China. Urban Planning, no. 5. 73-76. [in Chinese].

Zhou, Y. and Ma, L. (2003) China's urbanization levels: reconstructing a baseline from the Fifth Population Census. China Quarterly, 173, 176-196.

Zhu, X.D., Huang, L. and Zhang, X.S. (2000) Housing and Economic Development in Suzhou, China: A New Approach to Deal with the Inseparable Issues, No. W00-4, Joint Center for Housing Studies, Harvard University, Cambridge, MA.

\section{Endnotes}

${ }^{1}$ Less than $1 \%$ of household income, according to Wang and Murie (1999).

${ }^{2}$ During China's Cultural Revolution (1966-1976).

${ }^{3}$ In China, all land belongs to the state and is leased for housing development. The land lease period is normally 70 years.

${ }^{4}$ Before 1978 , only about 100 million $\mathrm{m}^{2}$ of new rural houses were built each year, but by 1986 this figure had reached 980 million $\mathrm{m}^{2}$ (McKinley and Wang, 2002). 
${ }^{5}$ Since 1984, China's government has allowed peasants to enter towns for permanent settlement on the condition that they look after their own needs for food and other welfare and will not cause new burdens upon the state (Lin, 2007).

${ }^{6}$ The definition of 'urban population' in China has changed in each of the five censuses carried out in 1953, 1964, 1982, 1990 and 2000. The pre-1982 statistical data series of urban population was readjusted by the 1982 definition by the National Bureau of Statistics of China in 1984 (Liu et al., 2003). China's ever-changing official definitions of urban settlements have made it extremely difficult to give an accurate estimate of the magnitude of urbanization, though serious scholarly evaluations suggest that the official estimate was 'a reasonable figure' not far from the actual situation (Zhou and Ma, 2003, p. 176; Chan and $\mathrm{Hu}, 2003$, p. 64).

${ }^{7}$ Similar to Japanese wooden detached houses (about 13-40 years) (Komatsu et al., 1994; Hashimoto et al., 2007).

${ }^{8}$ The result is actually bigger than real internal migration flow because some people become urban without moving due to the growth and reclassification of towns and surrounding areas into urban districts.

${ }^{9}$ In the countryside, 'hollow villages' have become increasingly common. As peasants' incomes increase, they build new and larger houses, often on the outskirts of the villages encroaching on nearby farmland, rather than renovate their existing homes. As villagers move to their new houses on the outskirts, the village becomes 'hollow' as the old parts of the village become increasingly empty of people (Lin, 2007, p. 1848).

\section{Appendix A: Calculation of internal migration flow}

Net internal migration is calculated from the mass balance of the processes with population stocks. As illustrated in Figure 1, the balance equations for urban and rural population stocks are:

$$
\begin{gathered}
\frac{\mathrm{d} P_{r}}{\mathrm{~d} t}=\left(i_{\mathrm{r}}-e_{\mathrm{r}}\right)+\left(b_{\mathrm{r}}-d_{\mathrm{r}}\right)-\left(m_{\mathrm{u}}-m_{\mathrm{r}}\right) \\
\frac{\mathrm{d} P_{u}}{\mathrm{~d} t}=\left(i_{\mathrm{u}}-e_{\mathrm{u}}\right)+\left(b_{\mathrm{u}}-d_{\mathrm{u}}\right)+\left(m_{\mathrm{u}}-m_{\mathrm{r}}\right)
\end{gathered}
$$

The net internal rural-urban migration flow $\left(m_{\mathrm{u}}-m_{\mathrm{r}}\right)$ can be obtained when the net migration flow $\left(i_{\mathrm{r}}-e_{\mathrm{r}}\right)$ or $\left(i_{\mathrm{u}}-e_{\mathrm{u}}\right)$ and natural population growth $\left(b_{\mathrm{r}}-d_{\mathrm{r}}\right)$ or $\left(b_{\mathrm{u}}\right.$ $-d_{\mathrm{u}}$ ) are known. However, net migration and natural population growth are not specified for rural and urban areas in China. The equations have to be converted to adopt the readily available national data. The balance equation for the nation is resulted by adding (A1) and (A2) together:

$$
\frac{\mathrm{d} P}{\mathrm{~d} t}=(i-e)+(b-d)
$$

where $P\left(=P_{\mathrm{r}}+P_{\mathrm{u}}\right)$ is the total national population; $i$ $\left(=i_{\mathrm{r}}+i_{\mathrm{u}}\right)$ and $e\left(=e_{\mathrm{r}}+e_{\mathrm{u}}\right)$ are total immigration and emigration; and $b\left(=b_{\mathrm{r}}+b_{\mathrm{u}}\right)$ and $d\left(=d_{\mathrm{r}}+d_{\mathrm{u}}\right)$ are natural population change from birth and death at year $t$ in China.
In China, at a national level, the net migration rate $(=(i-e) / P)$ as well as birth rate $(=b / P)$, death rate $(=d / P)$, and natural population growth rate $(=(b-d) / P)$ are available in time series in China Statistical Yearbooks (National Bureau of Statistics of China (NBSC), 2005, 2007). China's future net migration rate, birth, and death rate by 2050 can be found in the projections of United Nations Population Division (UNPD, 2006). The historical figures and UNPD projection show that net migration flow through China's borders is significantly smaller than the natural population change: less than $1 \%$ of natural population growth in most early years and around $5 \%$ in the last five years. The net migration flows $(i-e),\left(i_{\mathrm{r}}-e_{\mathrm{r}}\right)$, and $\left(i_{\mathrm{r}}-e_{\mathrm{r}}\right)$ are neglected and equations (A1), (A2) and (A3) are simplified as:

$$
\begin{gathered}
\frac{\mathrm{d} P_{\mathrm{r}}}{\mathrm{d} t} \approx\left(b_{\mathrm{r}}-d_{\mathrm{r}}\right)-\left(m_{\mathrm{u}}-m_{\mathrm{r}}\right) \\
\frac{\mathrm{d} P_{\mathrm{u}}}{\mathrm{d} t} \approx\left(b_{\mathrm{u}}-d_{\mathrm{u}}\right)+\left(m_{\mathrm{u}}-m_{\mathrm{r}}\right) \\
\frac{\mathrm{d} P}{\mathrm{~d} t} \approx(b-d)
\end{gathered}
$$

Assume both rural and urban regions have a same natural population growth rate as the national one. According to the definition of urbanization rate $u$ as $u=P_{\mathrm{u}} / P$, the net internal rural-urban migration flow $\left(m_{\mathrm{u}}-m_{\mathrm{r}}\right)$ can be obtained by equation (A4) or (A5), based on the change of rural or urban population stock:

$$
\begin{gathered}
\left(m_{\mathrm{u}}-m_{\mathrm{r}}\right) \approx(b-d)(1-u)-\frac{d(P \cdot(1-u))}{\mathrm{d} t} \\
\left(m_{\mathrm{u}}-m_{\mathrm{r}}\right) \approx \frac{d(P \cdot u)}{\mathrm{d} t}-(b-d) u
\end{gathered}
$$

where

$$
u=\frac{P_{\mathrm{u}}}{P},(i-e) \approx 0,\left(i_{\mathrm{r}}-e_{\mathrm{r}}\right) \approx 0,\left(i_{\mathrm{u}}-e_{\mathrm{u}}\right) \approx 0
$$

and

$$
\frac{b-d}{P} \approx \frac{b_{\mathrm{r}}-d_{\mathrm{r}}}{P_{\mathrm{r}}} \approx \frac{b_{\mathrm{u}}-d_{\mathrm{u}}}{P_{\mathrm{u}}}
$$

Fed with historical figures of $b, d, u, P$ from the NBSC between 1949 and 2007, and the forecasting data from UNPD's medium scenario, the results of $\left(m_{\mathrm{u}}-m_{\mathrm{r}}\right)$ calculated from equations (A4) and (A5) are slightly different (less than 1\%). The net internal ruralurban migration in China is calculated as the average of the results from the two equations and is illustrated in Figure A1. 

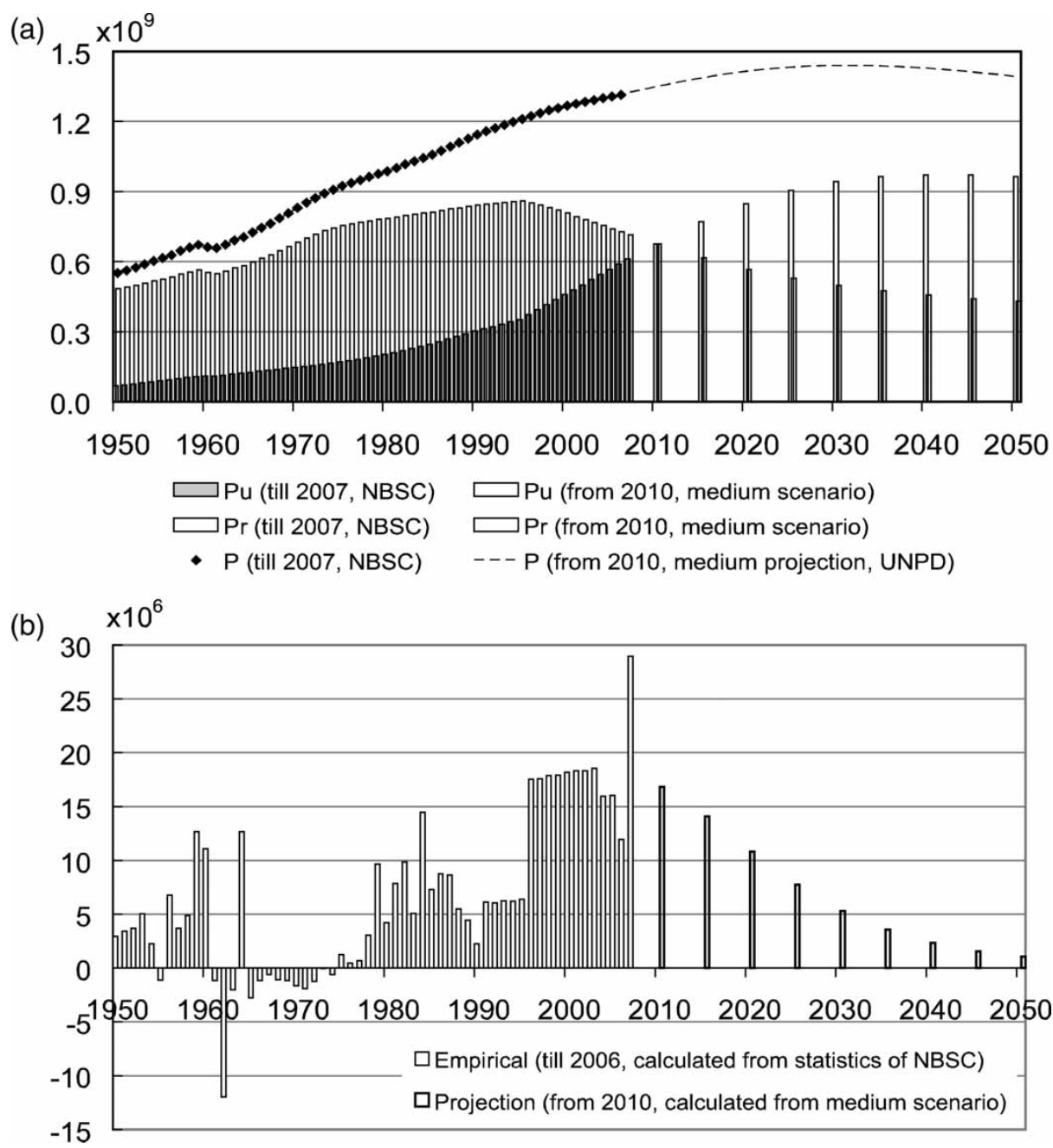

Figure A1 Population components and net internal rural-urban migration in the medium scenario. Data before 2006 are historical figures derived from the National Bureau of Statistics of China (NBSC) (1984-2007, 2005); forecasting data for China's national population are quoted from United Nations Population Division (UNPD) (2006); the future urbanization rate is the medium variant of the study with a saturation level at 70\%: (a) rural $\left(P_{\mathrm{r}}\right)$ and urban $\left(P_{\mathrm{u}}\right)$ population in China; and $(\mathrm{b})$ net internal rural-urban migration in China

Figure A1(a) illustrates the development of China's population and its rural and urban components. The national population after 2007 is quoted from the UNPD's medium projection, which shows that China's population will peak by 2030. Matching with the urbanization rate in the medium scenario of this study, the urban population in China, which has been increasing quickly recently, will overtake the rural population in about 2010, and will reach a saturation point around 2040. The rural population in China, which started to shrink in 1995, will keep declining in the first half of the 21st century. Figure A1(b) shows that China has experienced the biggest internal migration period since 1996 with a yearly migration of more than 15 million for a decade. After a drop during 2004 and 2006, the number dramatically jumps to near 29 million at 2007 . The combined result of the total national population growth and the urbanization trend foresees a steady decrease till the end of 2050, and around 300 million people in China will shift their lifestyle from rural to urban by that time.

\section{Appendix B: Stock dynamics model for housing floor area}

The generic stock dynamics model developed by Müller is applied for rural and urban housing stock individually. The central equations are as follows:

$$
\begin{gathered}
A_{\mathrm{r}}(t)=P_{\mathrm{r}}(t) \cdot A_{\mathrm{rc}}(t)=P(t) \cdot(1-u(t)) \cdot A_{\mathrm{rc}}(t) \\
A_{\mathrm{u}}(t)=P_{\mathrm{u}}(t) \cdot A_{\mathrm{uc}}(t)=P(t) \cdot u(t) \cdot A_{\mathrm{uc}}(t) \\
\frac{\mathrm{d} A_{\mathrm{r}, \text { out }}(t)}{\mathrm{d} t}=\int_{t_{0}}^{t} L_{\mathrm{r}}\left(t, t^{\prime}\right) \cdot \frac{A_{\mathrm{r}, \mathrm{in}}(t)}{\mathrm{d} t} \mathrm{~d} t^{\prime}
\end{gathered}
$$




$$
\begin{gathered}
\frac{\mathrm{d} A_{\mathrm{u}, \text { out }}(t)}{\mathrm{d} t}=\int_{t_{0}}^{t} L_{\mathrm{u}}\left(t, t^{\prime}\right) \cdot \frac{A_{\mathrm{u}, \text { in }}(t)}{\mathrm{d} t} \mathrm{~d} t^{\prime} \\
L_{\mathrm{r}}\left(t, t^{\prime}\right)=\frac{1}{\sigma_{\mathrm{r}} \sqrt{2 \pi}} \cdot e^{-\frac{\left(t-t^{\prime}-\tau_{\mathrm{r}}\right)^{2}}{2 \sigma_{\mathrm{r}}^{2}}} \\
L_{\mathrm{u}}\left(t, t^{\prime}\right)=\frac{1}{\sigma_{\mathrm{u}} \sqrt{2 \pi}} \cdot e^{-\frac{\left(t-t^{\prime}-\tau_{\mathrm{u}}\right)^{2}}{2 \sigma_{\mathrm{u}}^{2}}} \\
\frac{\mathrm{d} A_{\mathrm{r}, \text { in }}(t)}{\mathrm{d} t}=\frac{\mathrm{d} A_{\mathrm{r}}(t)}{\mathrm{d} t}+\frac{\mathrm{d} A_{\mathrm{r}, \text { out }}(t)}{\mathrm{d} t} \\
\frac{\mathrm{d} A_{\mathrm{u}, \text { in }}(t)}{\mathrm{d} t}=\frac{\mathrm{d} A_{\mathrm{u}}(t)}{\mathrm{d} t}+\frac{\mathrm{d} A_{\mathrm{u}, \text { out }}(t)}{\mathrm{d} t}
\end{gathered}
$$

Equations (B1) and (B2) indicate that urban and rural housing stocks are determined by the size of the national population, the level of urbanization, and per capita housing demand in either region. Equations (B3) and (B4) illustrate that the outflow from the housing stock is determined by the past inflow, with a delay of the service life of the houses. Equations (B5) and (B6) assume that the lifetimes of rural and urban houses follow a normal distribution function. Equations (B7) and (B8) forecast the future rural and urban inflows of the housing stock by balancing the rural and urban housing processes, respectively.

\section{Appendix C: Various forecasts for the urbanization rate in China}

Various forecasts for the future urbanization trend in China and the variants adopted in this study are illustrated in Figure C1. Previous forecasts are all projected only to 2050, where the data in the China Energy Strategy (2000-2050) and those from the Center of China Population Information Research (Shen et al., 2005) are available for ten-year steps, while the UNPD's urbanization prospects are available for five-year steps.

\section{Appendix D: Urban per capita floor area as a function of gross domestic product per capita}

The parameter per capita floor area represents people's living standard. Based on the hypothesis that the wealthier people are, the more affluent living space they demand, this parameter can be considered a function of the socio-economic variables such as gross domestic product (GDP). As illustrated in Figure D1, previous housing case studies (Hu et al., 2010a; Bergsdal et al., 2007a; Müller, 2006) show a strong logarithmic regression relationship between per capita floor area and local GDP per capita. For purposes of comparison, this study adopts a variant of per capita floor area as a function of per capita GDP. Historical figures of floor area and GDP are used to calibrate the regression formula. The future GDP growth quoted from the World Economic Outlook Database for 2008-2013 and other economists' forecasts (Guest and McDonald, 2007) are used for per capita floor area projection. The resulting urban per capita floor area as a function of per capita GDP is shown in Figure 2(d), with other variants and the sensitivity analysis for the different projections shown in Figure 5.

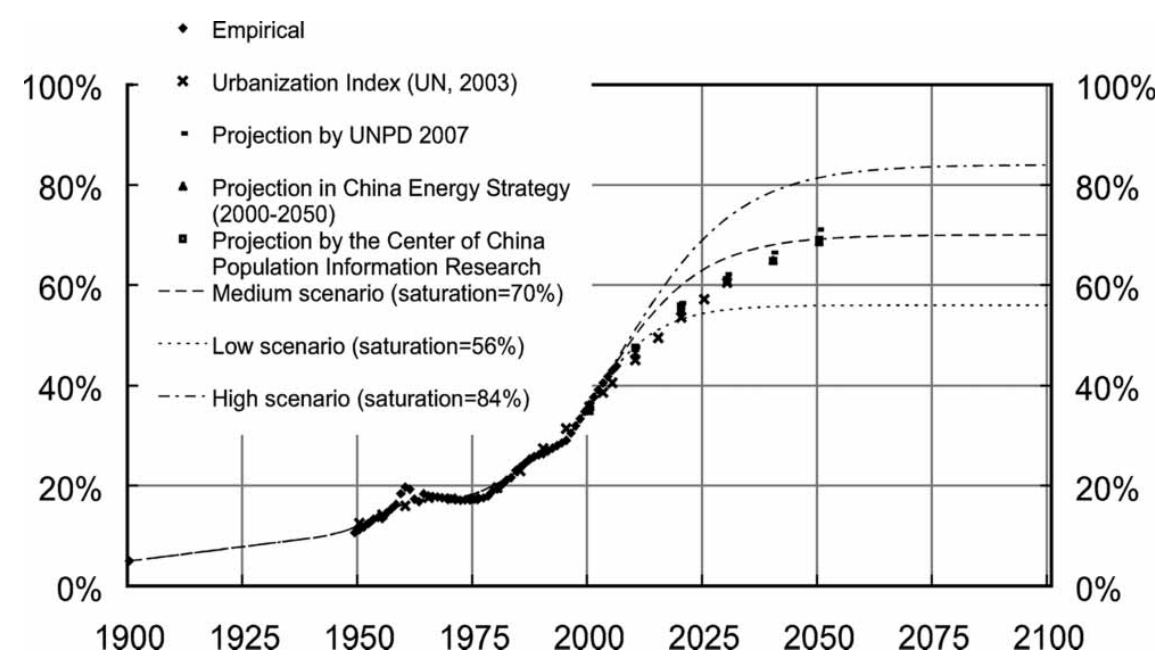

Figure C1 Various forecasts for the urbanization rate $\left(U_{\mathrm{r}}\right)$ in China. Empirical data until 2006 are derived from the National Bureau of Statistics of China (NBSC) (1980-2008, 2005). 


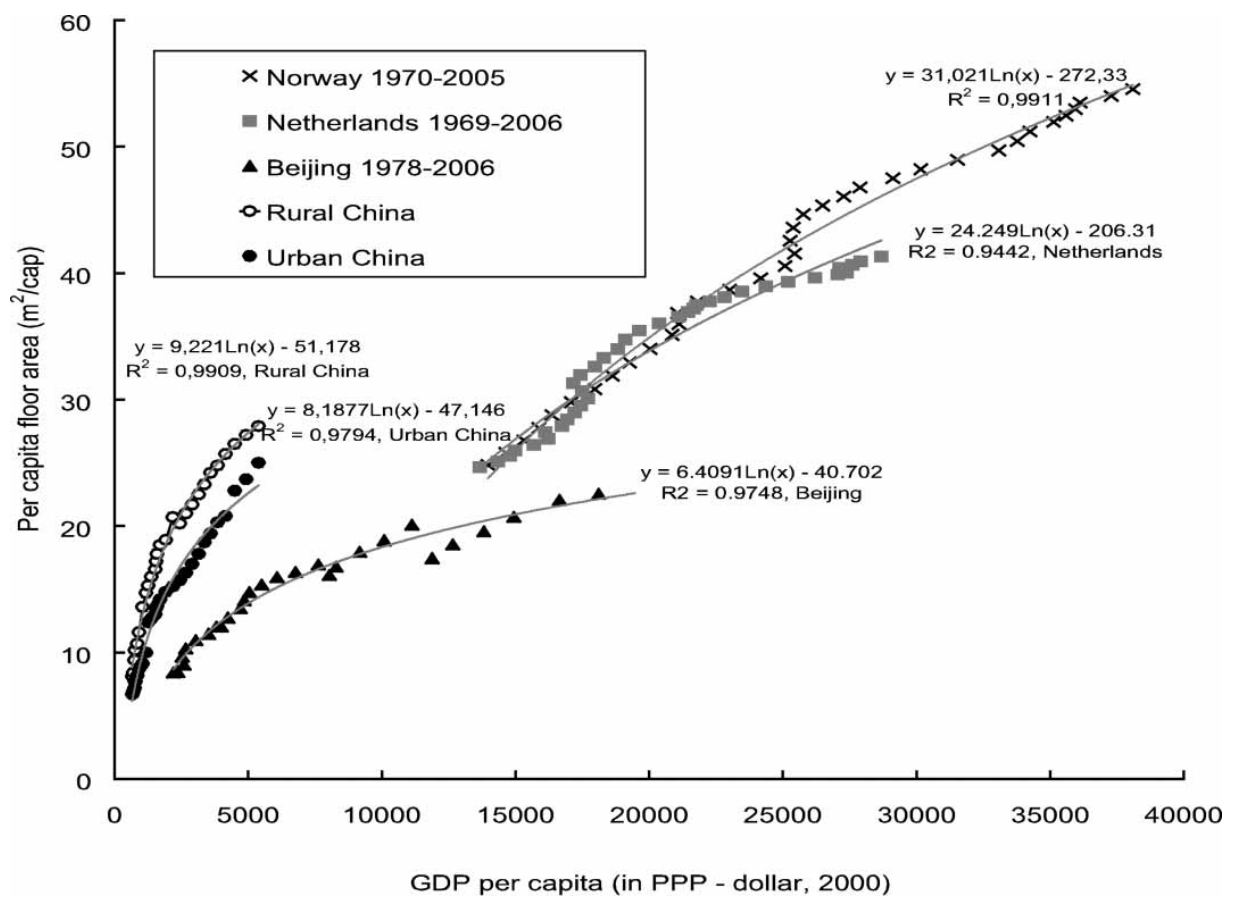

Figure D1 Relation between floor area per capita and gross domestic product (GDP) per capita. Sources: Bergsdal et al. (2007a); Müller (2006); National Bureau of Statistics of China (NBSC) (1984-2007, 2005); Eurostat (2009); The World Bank (2008). 